\title{
Economic valuation of environmental goods and services
}

\author{
Alda Matos $^{1 *}$, Paula Cabo ${ }^{2}$, Isabel Ribeiro ${ }^{2} \&$ António Fernandes ${ }^{2}$ \\ ${ }^{1}$ Polytechnic Institute of Bragança, Portugal \\ ${ }^{2}$ CIMO - Mountain Research Centre, Portugal
}

\begin{abstract}
The economic valuation of environmental goods and services (EVEG\&S) results of the increasing concern with the quality of industrial products and the reduction of social welfare. The EVEG\&S presents the direct and indirect costs and benefits of quantitative and qualitative environmental changes in goods and services and corresponding impacts. This is particularly important in the valuation of investment projects and governmental policies. This study consists in a survey of environmental appraisal methods, focusing into the hypothetical and complementary market based ones. The review reveals that evaluation of environmental quality is very complex. In fact, for each criterion there are several assumptions that are inapplicable to all situations. Effectively, despite the evident complementarity of conventional goods environmental quality, the values attributed to these resources could be underestimated and complementary and substitute markets can be inefficient parameters.
\end{abstract}

Keywords: Economic valuation, natural resources, markets, environmental goods

\section{Introduction}

The economic growth is based on wealth creation, based on a process of dominance and transformation of the Nature. The modern society is guilty of wild exploitation of natural resources, neglecting the damages of productive activities. The demand and improper use of the natural resources increases daily. With this speedy environmental harm, environmental protection stands out as one of the current and future major challenges for humanity. The economic appraisal of environment results of the increasing concern with protection and preservation of natural resources and consumers' requests for quality industrial products, simultaneous with the reduction of social welfare, as consequence of the quality and amount of these resources. The economic appraisal emerges as a measuring tool of environmental goods and services and of the impacts of environmental degradation and depletion, determining the direct and indirect costs and benefits of qualitative and quantitative changes. It is gathering importance in the evaluation of investment projects, governmental policies and international trade. This paper focuses on this problematic. The paper consists of a critical analysis of the economic appraisal criteria of environmental goods and services. Particularly of the methods that make use of hypothetical and complementary market goods.

\section{Economic Valuation of Environmental Goods and Services}

Based on the externality notion, Foladori (1997) defends that negative trends inherent to free market can be beated through environmental appraisal with the inclusion of prices in economic analysis, via policies that attenuate environmental problems. Schweitzer (1990) beliefs that environmental appraisal is fundamental to prevent the depletion of natural resources.

The environmental appraisal emerges as a set of techniques and methods to quantify the expectations of benefits/costs derived from the use of environmental assets, carrying out

\footnotetext{
* Corresponding author. Tel.: (+351) 273303242 - Fax: (+351) 273325405

Email address: alda@ipb.pt
} 
benefittings or infliction of environmental damages. The economic value of an environmental good consists of the estimate of a monetary value for this good, in opposition to other available goods. However, some times, it's difficult to aggregate all the effects in a single indicator.

The economic value of environmental resources (EVER) results from its attributes, and these can be associated to the use (direct, indirect and option) or non-use of the resource, i.e., its simple existence. EVER purposes a fee for environmental resources' use and/or preservation. The genesis is the protection of current and future generations' interests. Thus, use value (UV) is the value attributed by people who use or usufruct of the environmental good to satisfy their needs. The non use value (NUV) is dissociate of the use because it derives from a moral, cultural, ethical or altruistic position regarding the rights of existence of other living species or the preservation of natural assets although that do not represent current or future use for them.

While slightly different classifications exist, they result the same. Still, controversy subsists regarding existence $(\mathrm{EV})$ and option $(\mathrm{OV})$ values, since the EV represents the individual will to preserve a set of environmental resources for future generations' direct and/or indirect use. Thus, the conceptual question is if a value defined like so is closer associated with the OV or the EV. Equally, the legacy value (in this definition mixed with the EV) can be independent (Figure1). However, for EVER matters that the individuals point out the most trustworthy values possible, independently of the current or future use.

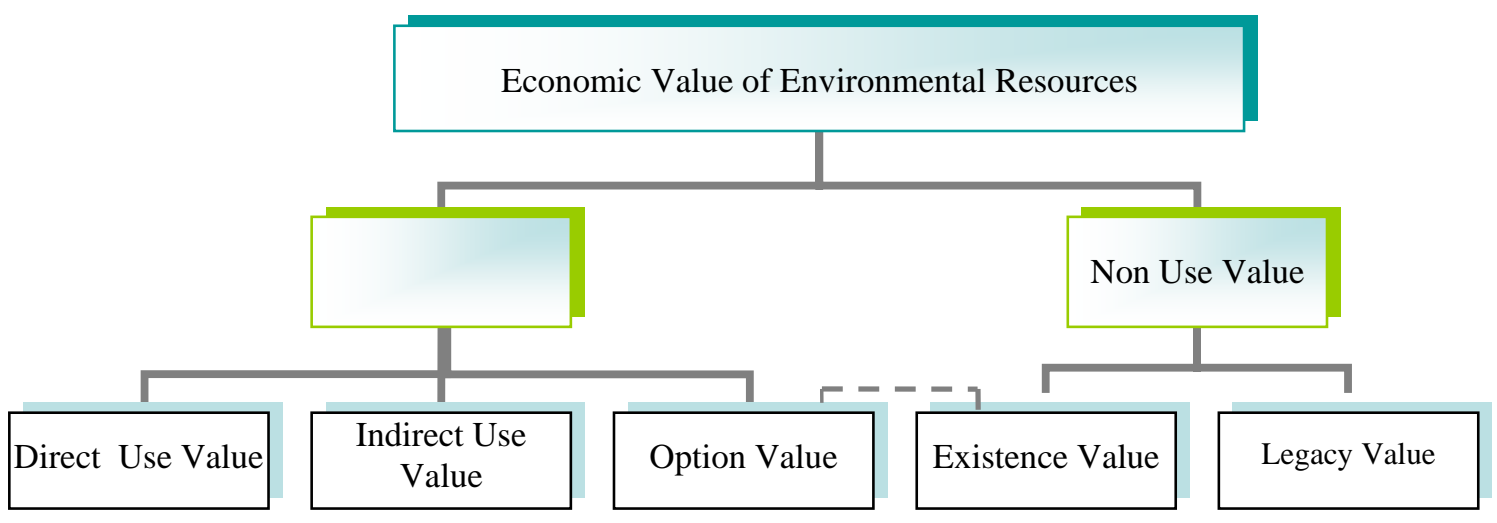

Figure 1: Different economic values of environmental resources

The environmental appraisal difficulty increases inversely as function of the resources' use. The choice of the criterion depends on the knowledge of the ecological dynamics of the study object, the purpose of the valuation, the availability of information and the hypotheses adopted.

Environmental economics classifies the valuation techniques in production function methods marginal productivity method and markets of substitute goods method - and demand function methods - methods that utilize markets of complementary goods (hedonic prices and travel costs methods) and hypothetical markets (method of contingent valuation). May and Motta (1994) refer that production function methods analyze environmental resources associated to the production of a private good and, generally, assume that supply variations do not influence market prices. The demand function methods admit that changes in resource availability modify individual wellbeing and, therefore, it's possible to identify individual measures of Willingness to Pay (WTP) or Willingness to Accept (WTA) regarding to these variations. These are the methods under this study review.

\subsection{Analysis of the Demand Function Methods}

To Dixon et al. (2001), subjective valuation methodologies can assess consumers revealed or expressed preferences, in real or fictitious markets, relating it with individuals' utility functions. Mainly, these methodologies use substitute market prices or contingent values (Table 1) 
Table 1: Subjective valuation criteria

\begin{tabular}{lll}
\hline Complementary Goods Market & & \\
\hline Hedonic Prices & & \\
Property value & Revealed behaviour & Substitute market prices \\
\cline { 2 - 3 } Wages differential & Revealed behaviour & Substitute market prices \\
\hline Travel Costs & Revealed behaviour & Substitute market prices \\
\hline Hypothetical Markets & & \\
\hline Contingent Valuation & Expressed behaviour & Contingent value \\
\hline
\end{tabular}

Revealed preferences analysis is based on real markets of goods and services (MG\&S) affected by environmental impact, in which folks pick between levels of environmental quality and other goods. When resources are not marketly traded, the economic analysis aims to estimate the economic value as if the market exists. The analysis of expressed behaviours is used when is not possible to valuate the environmental impacts, even dissimulatly, through real markets.

\subsubsection{Markets of Complementary Goods}

The urban amenities are not restricted to natural features, as green areas, beaches and climate. The concept also adds the goods (or evils) created by men, as traffic, pollution, recreation areas and safety. The study of these environmental attributes permits to understand the impact (and the changes) of the cities physical space on their inhabitants' wellbeing, as well as the effect on the real estate market value. To quantify urban amenities is not a simple task. Although the real estate market has supply, demand and an equilibrium price, it's not possible to visualize the market prices of environmental amenities, since trade of oxygen, landscape, recreation areas, or traffic, pollution and noise, does not exist.

The hedonic prices (MHP) and travel costs (TCM) models are the more adjusted criteria to decode this information. They are based in the preferences revealed by consumers in a substitute market, and use it to assess individuals' wellbeing, in view of environmental quality changes.

The MHP has been widely used in the real estate market to measure the marginal value of natural or structural attributes, and estimate the correlated social-environmental variables. This method is based on the recognition of the complementary attributes of a specific private composed good to environmental goods or services (Motta, 1998). This complementarity discloses the price of the environmental attribute implicit in the market price.

The method of property value (and wages differential method) solely valuates UV. It only looks into the appraisal of environmental functions/services that directly affect the market prices of related goods. The MHP considers a heterogeneous good as a closed package, with specific attributes, where the marginal price of each one is estimated, based on the analysis of the good observed value and attributes' respective amounts (Rosen, 1974). It presumes that families, when look for housing, are worried about what exists inside and outside (the amenities) of the property. These amenities (distance to workplace, proximity of parks, beach, schools, quality of air, water, sonorous pollution, landscape, etc.) will imply variations in the asset usufruct. Similarly, the price of a specific land does not depend solely on its patrimonial value, but also on the actual value of the net benefits generated by soil productivity over time. Thus, because productivity levels differ, different land fractions have different price levels. Additionally, the environmental features, as air quality, water disposal (for irrigation) or erosion, affect the soil quality for agriculture, and thus, its price. The MHP estimates the quantitative differences of the attributes, using market prices of goods or costs of services essentials in the formation of these prices/costs. These discrepancies are valued by individuals, reflecting their WTP when the environmental attributes vary. According to this paradigm, two houses with identical physical attributes, situated in different ecological and social contexts, will have different prices.

The MHP catches only the use values. EV is not catched because of the weak complementarity. When the demand for a specific environmental attribute is null, the demand for the composed 
good is also null. Redondo (1999) refers that MHP reproduces the changes in the UV of a specific place inhabitants, but are merely informative in the "passer-bys" case (individuals that do not have fixed residence there, but sporadically travel to it) and reveal nothing about NUV (associated with individuals that do not use the place). The adoption of this criterion requires the existence of a reasonable mobility in real state market, so that folks can reveal their WTP in an environmental context where is possible to choose between houses with different attributes and without prohibitive transaction costs (costs of house search and changing, taxes and duties associated with the sale/purchase). The improve of life quality conditions in a specific neighbourhood, does not necessarily imply a change in housing prices, due to the people weak mobility to try another neighbourhood and their WTP for usufruct of it.

Dixon et al. (1994), Comune et al. (1995), Motta (1998), Redondo (1999), among others, emphasize that MHP efficient results require the assembling of detailed and faithful information on the characteristics of the asset under valuation. An exhaustive survey on the environmental indicators is crucial. Namely, the attributes that influence the assets price: property features (size, degree of conservation, benefittings); commercial, transport and education services; local community quality (neighbouring, criminality) and social-economic information of a sample representative of local owners. Additionally, the attribute under valuation must be clearly and precisely defined, in order to successfully isolate it from the subject other attributes. The same authors refer the operative difficulties in the econometrical estimation of the hedonic functions due to the omission of relevant variables, attributes' multicollinearity, and functional form identification, among others. Additionally, property prices can be underestimated due to minor property tax transfer or to attenuate the effect of patrimonial variations. The alternative would be to use leasing values. So, this method must only be used in case of high correlation between property price and environmental attribute, when is possible to catch all the attributes influencing the real estate market equilibrium price and when the hypotheses adopted for the estimate of the consumer surplus are realistic.

The TCM is used in the valuation of environmental resources as parks and recreational sites, but also to quantify externalities of urban collective transport projects. The TCM basic premise is that the costs of accessing to a place directly influence its visits number. This method associates the environmental resources value to its recreation value. The benefits of a specific investment are quantified in function of the (estimated costs by the) curve of demand of the activity, based on the study of their users' expenditures (in time and transportation costs).

The TCM is based on a preferences approach. The individual reveals his choices buying specific goods associated with the use of an environmental good. This approach requires interviews to the visitors in order to determine their standard use and to gather information on the number of visitors; visitors' geographic, social and economical characteristics; motive, duration and frequency of the visit; transportation mean and costs associated to the trip... The data collected will be used to estimate a visitation rate by region of origin, the total travel costs and link it with the visits frequency, establishing a demand correspondence. Each individual income matches a demand function, given that each person is WTP a determined price in exchange for an amount of the product. The curve of demand for visit for each region and the aggregated demand curve are determined. Then, visitation demand function is used to estimate the consumer surplus, which represents the economic value of the recreational site.

The disadvantages of the TCM application are related with the individual visits' duration, the possibility of resources deterioration, the distance (it's expected that distant residents visit less the recreational site, while they can actually have longer visits), the difficulty in the exclusion of services not associated to the site (multiple trip objectives and destinations), the merely capture the visits direct and indirect UV and the monetary value of the time spent by the visitor (overvaluing the recreation cost, due to price distortions in the labour market). Other disadvantages are related with the premises assumed in the estimation of the curve of demand; the need of reliable data; high application costs; dependency of statistical methods; and the no consideration of NUV components. 


\subsubsection{Hypothetical markets}

To Hicks (1939), the estimation of a change in consumer wellbeing can be carried out by its income variation, introducing two measures of value that support the economic valuation of environmental impacts. The measures are compensatory and equivalent variations and are linked with variations in consumers' utility and preferences (WTP and WTA).

According to Comune et al. (1995), the Method of Contingent Valuation (MCV) aggregates a set of techniques used in research to estimate the EVEG\&S, based on consumers' preferences. These techniques are based on individual budgetary evaluations, given an increase or decrease in the quality or amount of an environmental good or service, in a hypothetical scenario. This is the only method that allows valuating the UV and NUV of environmental resources. Its domain of application is the valuation of wildlife, protection of habitats and measurement of the UV of leisure and recreational sites. According to Dixon et al. (1994), the MCV constitutes the only alternative to attain economic value estimates when in presence of distortions in environmental MG\&S, there are no effective market nor substitute markets for it. Walnut et al. (2000) explain that the theoretical concept of MCV is consumer theory (consumer choice and consumer surplus). The individual WTP discloses, through the graduation of the marginal utility, the best estimate of its demand scale, and thus, quantifying social welfare measures. The consumer choices are based on the utility maximization premise, under budgetary restriction. The consumer surplus valuates the different degrees of individuals' preferences for various goods and services revealed when consumers go to the market and pay a specific amount for them.

The MCV uses questionnaire techniques to valuate consumers expressed preferences, and clearly describe the good to quantify. In order to the respondents declare and quantify their real preferences, this method simulates scenarios with characteristics analogous to the existing in the real world. Based on personal opinions, constructs a hypothetical market and quantify WTP (payment for a wellbeing improvement) and WTA (reimbursement for a wellbeing loss) according to variations in the availability of environmental resources. The intended result is to reach maximum WTP for a given benefit, the minimum compensation to abdicate of the benefit or WTA for environmental damage. Finally, average WTP/WTA is calculated, the populations are added and thus obtaining the estimates of the value attributed to the environmental good.

Comune et al. (1995: 64) point out that one of the advantages of this type of methodology consists, precisely, of producing estimates of values that could not be obtained by other ways. To Macedo (2002), the limitations of these methods derive from individuals apparently contradictory behaviours, according with the roles adopted in face of the environmental good. The author refer that most of the folks is propense to establish extremely high values to admit the loss of a natural resources and excessively low values in the hypothesis of having to pay to assure the it protection.

The MCV can bear ambiguous results due to bias, resulting from the market fictitious feature and from quality of the individuals' information. The respondents can not reveal the real WTP or WTA due to their reduced experience, mostly for the WTA case. Moreover, the interviewer can induce answers. And, having no commitment with an effective payment, the vehicle used can affect the result.

\section{Final remarks}

This paper describes several methodologies of evaluation of environmental goods, showing that the quantification of environmental quality is not simple to get. None of the different existing methods adjust to all situations. Each criterion is limited to specific conditions, and therefore unacceptable and inapplicable in others.

The economic indicators are precious tools for unique decision making, however, as society general knowledge of ecosystem functions is reduced, they become limited, consequently overvaluing individual preferences, that is, overvalue a subsystem in detriment of another possibly more valuable for the project. Therefore, the EVEG\&S incurs in an implicit 
subjectivity of the importance of the scale and the definition of object of study. With the existing subjectivity, we can argue about the multiplicity of the value, since different exercises of quantification origin distinct results, according to the purpose and the methodology applied. Such multiplicity does not reduce the importance of the valuation as an analysis technique, but, each result can be influenced by different perspectives, and, thus alerting to the values' partiality. The EVEG\&S should be executed in partnership by environmental, social scientists and economists, with inter, trans and multidisciplinary dimension to avoid the risk of indiscriminately choose methods inadequate to the reality in study. The EVEG\&S is of extreme utility for the decision making, but has limits of scientific uncertainty that go beyond economic science. Therefore, it would be of all interest a bigger scientific cooperation in this area, in order to increase quality to the current state of the art, since the resources' values can be underestimated and the complementary or substitute markets can be inefficient parameters.

\section{References}

Comune, A.; Grasso. M.; Tognella, M. and Schaeffer, Y.,1995.Aplicação de Técnicas de Avaliação Econômica ao Ecossistema Manguezal. Valorando a Natureza.

Dixon, J.; Scura, L.; Carpenter, R. and Sherman, P.,1994. Economic Analysis of Environmental Impacts. Earthscan Publications Ltd. London.

Foladori, G., 1997. A Economia Frente à Crise Ambiental. Revista de Economia, 23(21).

Hicks, J., 1939. The Foundations of Welfare Economics. Economic Journal, 49:696-712.

Loomis, J. and González-Cabán, A., 1998. A Willingness to Pay for Protecting Acres of Spotted Owl Habitat from Fire. Ecological Economics, 25:315-322.

Loomis, J.; González-Cabán, A. and Gregory, R., 1996. A Contingent Valuation Study of the Value of Reducing Fire Hazards to Old-growth Forests in the Pacific Northwest. Pacific Southwest Research Station. USDA, Forest Serv. Berkeley. CA.

Macedo, Z., 2002. Os Limites da Economia na Gestão Ambiental. Margem, 15:203-222.

May, P. and Motta, R., 1994. Valorando a Natureza: Análise Económica para o Desenvolvimento Sustentável. Editora Campus. Rio de Janeiro.

Motta, R., 1998. Manual para Valoração Económica de Recursos Ambientais. Ministério do Meio Ambiente, dos Recursos Hídricos e da Amazônia Legal, Brasília, 218p.

Moura, L., 2000. Economia Ambiental: Gestão de Custos e Investimentos. Ed. Juarez de Oliveira, S. Paulo, 200p.

Munasinghe, M., 1992. Environmental Economics and Valuation of Development Decisions. Banco Mundial.

Nogueira, J.; Medeiros, M. and Arruda, F., 2000. Valoração Econômica do Meio Ambiente: Ciência ou Empirismo? Cadernos de Ciência e Tecnologia, 17(2):81-115.

Pearce, D. and Turner, R., 1990. Economics of Natural Resources and the Environment. Harviester Wcatsheag, The Johns Hopkins University, Baltimore.

Redondo, O., 1999. Entre la Economia y la Naturaleza. La Controversia sobre la Valoración Monetaria del Medio Ambiente y la Sustentabilidad del Sistema Económico. Los Libros de la Catarata, Madrid.

Rosen, S., 1974. Hedonic Price and Implicit Markets: Product Differentiation in Pure Competition. Journal of Political Economics, 82:34-55.

Santos, R.; Martinho, S. and Antunes, P., 2001. Avaliação Económica dos Impactes Ambientais do Sector Eléctrico. Estudo Sobre o Sector Eléctrico e Ambiente. $2^{\circ}$ Relatório. Centro de Economia Ecológica e Gestão do Ambiente, Universidade Nova de Lisboa.

Schweitzer, J., 1990. Economics, Conservation and Development: a Perspective from USAID. In: Vicent, J.; Crawfor, E. and Hoehn, J. (eds). Valuing Environmental Benefits in Developing Countries: Proceedings. East Lansing, Michigan State University. 